\title{
A survey on the effects of knowledge management on organizational learning: A case study of banking industry
}

\author{
Hamid Reza Bahrami ${ }^{a}$, Mohammad Oghbaei Jazani ${ }^{\text {* }}$ and Manouchehr Joybar ${ }^{\mathrm{c}}$
}

${ }^{a}$ Department of Management and Accounting, Science and Research Branch, Islamic Azad University, Isfahan, Iran

${ }^{b}$ Ph. D. Student, Department of Management and Accounting, Science and Research Branch, Islamic Azad University, Isfahan, Iran

${ }^{c}$ Department of Management, Mahabad Branch, Islamic Azad University, Mahabad, Iran

\section{CHRON I C L E A B T T A C T}

Article history:

Received August 19, 2013

Received in revised format

19 September 2013

Accepted 7 November 2013

Available online

November 82013

Keywords:

Organizational Culture

Knowledge-Based Strategies and

Policies

Organizational Learning

Sharing and Knowledge Dividing

Senior Management Support

\begin{abstract}
The aim of this study is to investigate the relationship between critical success factors of knowledge management and organizational learning and knowledge management strategies to improve learning in organizations. The proposed study investigates the effects of seven factors including information technology, human resources management, senior management support, knowledge-based strategies and policies, allocated rewards for employees, sharing and knowledge dividing and organizational culture on organizational learning. The proposed model of this paper has implemented regression technique and realized that strategy and human resource management played essential role on organizational learning. In addition, we have repeated the results using structural equation modeling and the results were similar with what we have found earlier using regression technique. In other words, in addition to two factors, human resource management as well as strategy, the study detected that information technology could also influence organizational learning.
\end{abstract}

\section{Introduction}

During the past few decades, there have been tremendous efforts on investigating the effects of intangible assets on the success of organizations. In fact, many people believe other tangible physical assets such as money, buildings and equipment cannot be considered as competitive advantage. Human resources, in fact, is the most influencing factor on the success on business units and knowledge is the primary key success for business development, knowledge management (KM) has been the focus of most organizations. The primary goal of applying KM in organizations is to adapt to rapidly changing environment of innovation, productivity and profitability (Davenport \& Probst, 2002; Maruyama, 1997). KM interaction as well as organizational learning play essential role on

* Corresponding author.

E-mail addresses:_m_oghbaei@ymail.com (M.Oghbaei) 
having sustainable market growth (Bennet \& Bennet, 2003). Therefore, as the organizations learn more, they are able to have better product through innovative and creative ideas (Azar \& Momeni , 2006). It is often essential to use KM only as an implicit form and using it directly seems to be difficult (Pourpasha et al., 2012). Knowledge is intellectual capital, which would change with time and if used effectively, most organizations are able to maintain a competitive position. Intellectual resources of the entire organization can contribute to most business units, significantly (Lin \& Lee, 2005; Bojamil, 2011). There are many studies to identify KM key success factors and many factors have been detected as the key success factors such as information technology, human resources, senior management support, knowledge-based strategies and policies, reward employees, sharing and knowledge dividing and organizational culture (McQueen \& Knussen, 2002). These days, many high tech firms are evaluated based on their knowledge and learning capabilities (Badrhaj, 2012).

During the past few years, there have been some changes on banking industry rules and regulations in Iran and the number of private banks has been increased, significantly. One primary question on learning more about the performance of banks is to learn more about the role of KM within banking industry (Sareban, 2011). This paper presents an empirical investigation to find important factors shaping organization learning. Accordingly, an essential question in this paper is the follows,

What are the key factors for the successful KM in organizational learning, what are the most important factors influencing employees who work for headquarters of the Banks in Iran?

The subject of this research is important in terms of international and domestic and there are not many studies devoted to the relationship between $\mathrm{KM}$ and organizational learning. The primary objective of this paper is to determine the key factors influencing on the success of knowledge management on organizational learning and the study is performed among employees who work in headquarters of some Iranian banks located in city of Tehran, Iran. The study also prioritize the key success factors of knowledge management on organizational learning, identifies weakness and strengths of banks and provides some necessary comments on improving the organizations. There are some related works on the effects of knowledge management on organizational learning, for instance, Akhavan et al. (2006) performed an empirical study to detect critical success factors influencing the success of KM. Shakouri and Khodareza (2012) investigated the effect of explicit and implicit vocabulary instruction on vocabulary knowledge of university students. Davenport and Probst (2002) did a survey at Siemens to study the effect of knowledge management to increase firm's competitive advantage, productivity and building sustainable growth. Mertins et al. (2003) investigated the success factors in knowledge management at IBM corporation. Knowledge management is in direct interaction with organizational culture and it is often difficult to exchange information within organization (Mayo, 1994). Any success in today's organizations to share information shall be considered as something important and many organizations try to manage and exchange their knowledge with their employees. In many cases, organizations are encouraged to share their knowledge through different platforms (Liebowitz, 2003; Radding, 1998).

\section{The proposed study}

This article has one major hypothesis and seven minor hypotheses as follows:

Main hypothesis: There is a relationship between some of the key success factors for knowledge management and organizational learning in the central departments of Banks in Iran.

The following also summarize various hypotheses of the survey, 
The first sub-hypothesis: There is a relationship between organizational culture and organizational learning in the central departments of Banks in Iran.

The second sub-hypothesis: There is a relationship between sharing of knowledge dividing and organizational learning in the central departments of Banks in Iran.

The third sub-hypothesis: There is a relationship between allocation of rewards for employee and organizational learning in the central departments of Banks in Iran.

The fourth sub-hypothesis: There is a relationship between knowledge-based strategies and policies and organizational learning in the central departments of Banks in Iran.

The fifth sub-hypothesis: There is a relationship between support of senior management and organizational learning in the central departments of Banks in Iran.

The sixth sub-hypothesis: There is a relationship between human resource management and organizational learning in the central departments of Banks in Iran.

The seventh sub-hypothesis: There is a relationship between use of information technology and organizational learning in the central departments of Banks in Iran.

Method of this research is practical for aspects of objective research method are descriptive - survey and correlation

\subsection{Data Collection Instrument}

In this study, questionnaire or the reliability coefficients were calculated using the method of measurement. Before distributing the questionnaire on a broad level, we have chosen a small group (n $=40$ ) and distributed the questionnaire among them. Cronbach alpha was calculated as 0.927, which is within desirable value.

\subsection{Operational definition of variables}

\subsubsection{Independent variables of Research}

Organizational culture: Culture is a set of key values that are widely accepted by members of the organization (Mayo,1994).

Sharing and dividing knowledge: The sharing of knowledge, skills and work experience is transferred between employees, which increases the learning of individuals is their (Akhavan\&et al,2006).

Allocation of rewards for employees: With regard to material and spiritual rewards for employees who provide their knowledge and skills are other colleagues, other employees also are encouraged to be active in sharing knowledge, which thus to encompass other employee (Liebowitz,2003).

Knowledge-based strategies and policies: All strategies of knowledge should be in line with organizational strategies to implement the one hand, knowledge management and organizational learning system implementation the other hand, increases the efficiency of the organization (Akhavan et al., 2006). 
Support of senior management: Senior management support for knowledge management systems, causes the acquisition, collection and transfer of knowledge was a more effective organization and learning increase efficiency in the organization (Davenport \& Probst, 2002; Maruyama, 1997).

Human resource management: Human resources are considered as an important asset in organizations, the optimal management of the employees' participation in exchanging knowledge, learning necessary skills need to determined. Human resource management is identification, selection, employment, train and develop manpower to achieve organizational goals (Akhavan et al., 2006).

Using information technology: A knowledge based groups, applications, email systems and other tools are helping to spread knowledge in a structured organization (Radding, 1998).

\subsubsection{Dependent variable of Research}

Organizational learning: The acquisition and application of knowledge, skills, values, beliefs and attitudes are used to maintain productive development organization (Marquardt, 1996). In other words, all the methods, mechanisms and processes within an organization to realize used for learning (Mayo, 1994).

\subsection{Statistical Population, Sample Size}

According to our survey, as of November, 2011, there were 2555 banks in city of Tehran, Iran and the sample size is calculated as follows,

$$
n=\frac{N \times z_{\alpha / 2}^{2} \times p \times q}{\varepsilon^{2} \times(N-1)+z_{\alpha / 2}^{2} \times p \times q},
$$

where $N$ is the population size, $p=1-q$ represents the yes/no categories, $z_{\alpha / 2}$ is CDF of normal distribution and finally $\varepsilon$ is the error term. Since we have $p=0.5, z_{\alpha / 2}=1.96$ and $N=2555$, the number of sample size is calculated as $n=93$. In our survey, we decided to distribute 120 questionnaires among the employees.

\section{Results and discussion}

We have performed normality test using Kolmogorov-Smirnov test and detected that all data were normally distributed. Therefore, the study uses one-way t-student test to examine various hypotheses of the survey. Table 1 demonstrates the summary of various factors.

\section{Table 1}

Results of single-sample $t$ test for independent and dependent variables

\begin{tabular}{lcccc}
\hline Factor & t-test & Standard deviation & Average & P-Value Sig.(2-tailed) \\
\hline Organizational culture & -1.215 & 0.99159 & 2.8839 & 0.232 \\
Sharing and dividing knowledge & -2.487 & 0.83412 & 2.7998 & 0.017 \\
Allocated for employee rewards & -5.219 & 0.91386 & 2.6191 & 0.000 \\
\hline Knowledge-based strategies and policies & -4.876 & 0.89667 & 2.6232 & 0.000 \\
Senior management support & -7.229 & 0.91133 & 2.5331 & 0.000 \\
Human Resource Management & -6.224 & 0.88277 & 2.5198 & 0.000 \\
\hline Using information technology & -0.078 & 0.97719 & 2.9986 & 0.951 \\
Organizational learning & -1.039 & 0.78131 & 2.9631 & 0.313 \\
\hline
\end{tabular}

\subsection{Simple linear regression analysis to test the research hypotheses}

In this section, a simple regression analysis is used to examine different research hypotheses. 


\subsubsection{The first sub-analysis and hypothesis testing}

The first hypothesis of the survey is associated with a relationship between organizational culture and organizational learning. The regression function between these two variables is as follows,

Organizational Learning $=1.461+0.517$ Organizational Culture $\quad R$-Square $=0.432$

As we can observe from the results of Eq. (2), there is a meaningful relationship between organizational culture and organizational learning. In other words, an increase of unit in organizational culture will increase 0.517 unit of organizational learning.

\subsubsection{The second sub-analysis and hypothesis testing}

The second hypothesis of the survey is associated with the relationship between organizational learning and sharing and knowledge distribution.

Learning $=1.149+0.641$ Sharing and knowledge R-Square $=0.486$ ANOVA (sig. $=.000)$

The result of regression model given in Eq. (3) clearly shows that there was a positive and meaningful relationship between organizational learning and knowledge sharing. In other words, an increase of unit in knowledge sharing will increase organizational learning by 0.641 .

\subsubsection{The third sub-analysis and hypothesis testing}

The third hypothesis of the survey is associated with the relationship between organizational learning and funds devoted for employee promotion.

Learning $=1.331+0.608$ Rewards $R$-Square =0.503 ANOVA $($ Sig. $=0.000)$

One more time, the result of regression model given in Eq. (4) specifies that there was a positive and meaningful relationship between organizational learning and funds dedicated to promote employees. In other words, an increase of unit in funds will increase organizational learning by 0.641 .

\subsubsection{Analysis and the fourth sub-hypothesis testing}

The next hypothesis of the survey is associated with the relationship between organizational learning and Knowledge-based strategies, policies.

Learning $=1.355+0.618$ Strategy R-Square $=0.492$ ANOVA $($ Sig. $=0.000)$

Similarly, the result of regression model given in Eq. (5) indicates that there was a positive and meaningful relationship between organizational learning and Knowledge-based strategies, policies. In other words, an increase of unit in funds will increase knowledge-based strategies, policies by 0.618.

\subsubsection{The fifth sub-analysis and hypothesis testing}

Another hypothesis of the survey is associated with the relationship between organizational learning and senior management support.

Learning $=1.617+0.539$ Senior management support $\mathrm{R}-$ Square $=0.421 \mathrm{Sig} .=0.000$ 
One more time, the result of regression model given in Eq. (6) specifies that there was a positive and meaningful relationship between organizational learning and Senior management support. In other words, an increase of unit in senior management support will increase organizational learning by 0.539 .

\subsubsection{The sixth sub-analysis and hypothesis testing}

Another hypothesis of this survey investigates the relationship between organizational learning and the effect of using information technology and the results of regression model is as follows,

$$
\text { Learning }=1.421+0.521 \text { IT R-Square }=0.439 \text { Sig. }=0.000
$$

It appears from the results of Eq. (8) that an increase of one unit on information technology could increase organizational learning by 0.521 and this confirms the sixth hypothesis.

\subsection{Relationship between independent and dependent variables, multiple linear regressions to investigate}

Table 2 demonstrates the results of our survey on measuring the relationship between organizational learning and all components of the survey using stepwise regression technique.

$$
\text { Learning }=0.745+0.261 \text { Strategy }+0.427 \text { Human resource management }+0.172 \text { IT }
$$

Table 2

Multiple logistic regression analysis between independent variables and organizational learning

\begin{tabular}{lcccc}
\hline Dependent variable & $\begin{array}{c}\text { Independent } \\
\text { variable }\end{array}$ & $\begin{array}{c}\text { ANOVA } \\
\text { (Sig.) }\end{array}$ & R-Square & $\begin{array}{c}\text { Coefficients } \\
\text { Constant }=0.745\end{array}$ \\
\hline Organizational culture & & & 0.069 & - \\
Sharing and knowledge sharing & & 0.421 & - \\
Allocated rewards for employee & Organizational & & 0.458 & Strategy $=0.261$ \\
Knowledge-based strategies and policies & learning & 0.747 & 0.005 & - \\
Senior management support & & & 0.898 & Human Resource Management $=0.427$ \\
Human Resource Management & & & 0.000 & IT $=0.172$ \\
Using Information Technology & & 0.002 & \\
\hline
\end{tabular}

As we can observe from the results of Table 2 and Eq. (9), strategy and human resource management will significantly influence organizational learning and it seems that human resource management could increase organizational learning relatively more than strategy could.

\subsection{Structural equations model (SEM)}

In this study the structural equations model analysis were used by LISREL 8.5 software. In order to achieve the best model, three-stage analysis was performed by LISREL software. The proposed model applies SEM model in three stages.

We first consider all seven independent variables and realize that some of the variables are not statistically significant. After two three steps, the results are achieved and Fig. 1 summarizes the results of our survey. As we can observe from the last results of SEM implementation given in Fig. 1, right side, there are three variables with significant impacts. In other words, the last part of regression model includes three components including strategy, human resource management and information technology and all statistical observations, RMSEA, P-value, GFI, AGFI are statistically significance. 


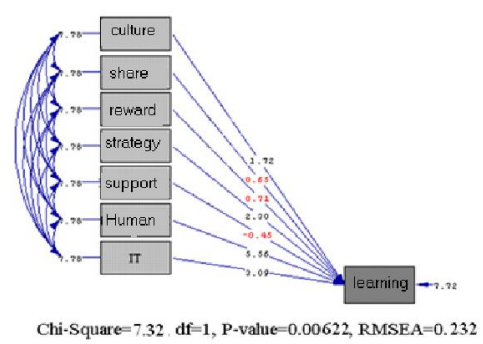

Initial model

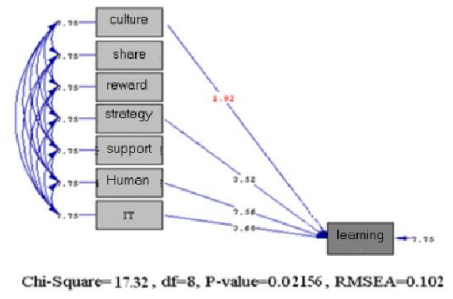

The modified model

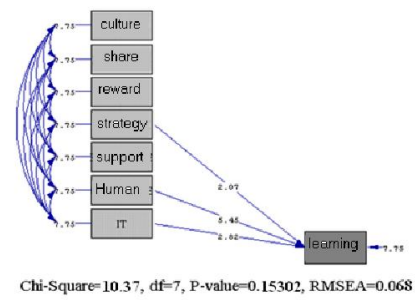

The final model

Fig. 1. The results of structural equation modeling

\section{Conclusion}

In this paper, we have presented an empirical investigation to study the effects of various factors on organizational learning. The proposed model of this paper has implemented regression technique and realized that strategy and human resource management played essential role on organizational learning. In addition, we have repeated the results using structural equation modeling and the results were similar with what we have found earlier using regression technique. In other words, in addition to two factors, human resource management as well as strategy, the study detected that information technology could also influence organizational learning. In other words, if we wish to increase the key success factors for knowledge management and organizational learning, we need to use knowledge-based strategies and policies, human resource management and use of information technology tools for success in organization.

\section{Acknowledgement}

The authors would like to thank the anonymous referees for constructive comments on earlier version of this paper.

\section{References}

Akhavan, P., Jafari, M., \& Fathian, M. (2006). Critical success factors of knowledge management systems. European business review, 18 (2), 97-113.

Azar, A., \& Momeni, M. (2002). Statistics and its application in management.Samt Publication-nd Volume (In Persian).

Azarakhsh, N. (2009). A study on knowledge management strategies based on business strategy, MS Thesis, Malek Ashtar University.

Badrhaj, M. (2012). Way towards improvement of information systems in business organizations. Middle East Journal of Scientific Research (MEJSR), 8, 66-75.

Bennet, A., \& Bennet, D. (2000). Characterizing the next generation knowledge organization. Knowledge and Innovation: Journal of the KMCI, 1(1), 8-42.

Bojamil, M. (2011). Evaluate the pattern of behavioral of employees based on organizational knowledge on Fuzzy Logic. Middle East Journal of Scientific Research (MEJSR), 5, 41-55.

Davenport, T. H., \& Probst, G. J. (2002). Knowledge management case book: Siemens best practices. John Wiley \& Sons, Inc..

Lin, H. F., \& Lee, G. G. (2005). Impact of organizational learning and knowledge management factors on e-business adoption. Management Decision, 43(2), 171-188.

Liebowitz, J. (2001). Knowledge management and its link to artificial intelligence. Expert systems with applications, 20(1), 1-6.

Marquardt, M. (1996). Building the learning organization. McGraw hill, New York, YN. 
Maruyama, G. (1997). Basics of structural equation modeling. Sage.

Mayo, A. (1994). The power of learning: a guide to gaining competitive advantage. IPD, house, London.

Mertins, K., Heisig, P., \& Vorbeck, J. (2003). knowledge management, concept and best practices, Springer.

Pourpasha, M.K., Radfar, R., Afshar Kazemi, M.A., \& Pourpasha, M.M. (2012). Application entropy method in identify the effective factors in success knowledge management on organizational learning, using fuzzy logic. Caspian Journal of Applied Sciences Research, 1(10), 19-30.

McQueen, R. A., \& Knussen, C. (2002). Research methods for social science. Prentice-Hall.

Radding, A. (1998). Knowledge management: Succeeding in the information-based global economy. Computer Technology Research Corp..

Sareban, (2011), Study of knowledge management in financial institutions based on BSC. World Applied Sciences Journal (WASJ), (10), 78-89.

Shakouri, M., \& Khodareza, M. (2012). The effect of explicit and implicit vocabulary instruction on vocabulary knowledge of university students. Caspian Journal of Applied Sciences Research, 1(11), 11-16. 